\title{
Prevalence of Glucose-6-Phosphate Dehydrogenase Deficiency Among Children in Eastern Saudi Arabia
}

\author{
Muneer H. Albagshi ${ }^{1}$, Suad Alomran ${ }^{2}$, Somaya Sloma ${ }^{2}$, Murtadha Albagshi ${ }^{3}$, Abdullah Alsuweel ${ }^{4}$, Helal \\ AlKhalaf ${ }^{4}$ \\ 1. Department of Pediatric Hematology, Hereditary Blood Diseases Center, Al-Ahsa, SAU 2. Department of Laboratories \\ and Blood Bank, Maternity and Children Hospital, Al-Ahsa, SAU 3. Department of Pediatrics, Maternity and Children \\ Hospital, Al-Ahsa, SAU 4. Department of Hematologic Technology, Maternity and Children Hospital, Al-Ahsa, SAU
}

Corresponding author: Muneer H. Albagshi, mbagshi@gmail.com

\begin{abstract}
Background

Glucose-6-phosphate dehydrogenase (G6PD) deficiency is the most common red blood cell enzyme deficiency worldwide. The disease is widely distributed in regions where malaria is prevalent, affecting mostly males because the enzyme is inherited as an X-link recessive pattern. In Saudi Arabia, we lack newborn screening (NBS) for G6PD deficiency, despite early reports about high prevalence.
\end{abstract}

Methods

This is a 10-year retrospective study of children who were screened for G6PD deficiency during their hospitalization between January 2008 to December 2017. The test was carried out using a qualitative fluorescence test suitable for mass screening to determine the prevalence of G6PD deficiency among the admitted children between 0 and 14 years of age.

Results

A total of 48,889 patients were screened which included 27,634 (56.5\%) males and 21,255 (43.5\%) females with a mean age of $1.93+3.98$ years. The overall prevalence of G6PD deficiency was $25 \%$, whereas it was $33.8 \%$ in the male subset and $13.2 \%$ in the female subset. Male sex was significantly correlated with G6PD deficiency. A total of 25,628 newborns were screened, with 14,219 (55.5\%) males and 11,409 (44.5\%) females, who had a G6PD deficiency prevalence of $18.8 \%$. There was a G6PD deficiency prevalence of $26 \%$ in males and $9.9 \%$ in females.

Conclusion

Review began 09/14/2020 Review ended 10/17/2020 Published 10/29/2020

\section{() Copyright 2020}

Albagshi et al. This is an open access article distributed under the terms of the Creative Commons Attribution License CC-BY 4.0., which permits unrestricted use, distribution, and reproduction in any medium, provided the original author and source are credited.
The present study confirms the high prevalence of G6PD deficiency in our community. Therefore, we need to establish an NBS program to screen for G6PD deficiency in order to prevent neonatal hyperbilirubinemia encephalopathy, avoidable hemolytic episodes, and to increase awareness among health practitioners.

\author{
Categories: Pediatrics, Healthcare Technology, Hematology \\ Keywords: hemolysis, saudi arabia, children, prevalence, glucose-6-phosphate dehydrogenase (g6pd)
}

\section{Introduction}

The enzyme glucose-6-phosphate dehydrogenase (G6PD) was discovered in 1932 by Walter Christian and Otto Warburg in red blood cells and yeast [1]. Moreover, severe anemia and hemoglobinuria were observed in children who ingested fava beans by pediatricians in Greece, Portugal, and Italy [2-3]. Favism is the term used to describe hemolysis triggered by the ingestion of fava beans in G6PD deficient individuals, and it ordinarily runs in families. Sulfa drugs used in treatment, as well as prophylaxis for malaria, lead to severe hemolysis [1]. The relationship between primaquine-sensitive patients and the G6PD enzyme was found to be $<15 \%$ of normal activity [4]. The G6PD gene is located on X.28 and inherited as an X-linked recessive [5]. G6PD is a housekeeping enzyme found in all human cells. Nicotinamide adenine dinucleotide phosphate (NADP) is reduced to NADPH in the pentose phosphate pathway. NADPH protects the red blood cells from oxidative damage [6-8]. This is the only pathway to generate NADPH. Therefore, in patients who are deficient in G6PD, these cells are damaged and undergo lysis, leading to acute hemolysis (Figure 1). In patients with G6PD deficiency with malaria, G6PD status does not impact baseline hemoglobin, parasitemia, temperature, or the outcomes of antimalarial therapy. The worldwide distribution of G6PD deficiency is mostly related to genetic abnormalities, ethnicity, and population migration. The relationship with malarial areas is obvious in Africa, South Asia, and the Middle East [9-10]. The prevalence of G6PD deficiency is 


\section{Cureus}

variable among the studied population, from less than $1 \%$ in Japan to up to $70 \%$ in Kurdish Jews [11-13]. In Saudi Arabia, the prevalence was $4.76 \%$ in a cross-sectional study and $14.7 \%-30.6 \%$ among newborns screened in Al-Ahsa and Qatif over one year [14-16]. In this study, we will review the prevalence of G6PD deficiency among all patients admitted to the Maternity and Children Hospital.

\section{Materials And Methods}

We reviewed all G6PD test results that were performed for the pediatric patients who attended the Maternity and Children Hospital in Al-Ahsa, Saudi Arabia, which is the main hospital for children and women's health. This retrospective study covered a 10-year period from January 2008 to December 2017. The pediatric population was defined as the age between 0 and 14 years.

We used the qualitative G6PD screening method by a fluorescence test suitable for mass screening in areas with a high prevalence of G6PD deficiency [17-18].

It used 5 microliters of whole blood with ethylenediaminetetraacetic acid (EDTA) anticoagulant added and mixed with 100 microliters of reagent at room temperature $\left(25^{\circ} \mathrm{C}\right)$ for 10 minutes. Ten microliters of the resulting solution were then placed on the paper provided, which was left to dry. After about 15 minutes in an incubator at $37^{\circ} \mathrm{C}$ with ultralight, the sample would fluoresce if G6PD was normal and would not fluoresce if G6PD was deficient. The reagent kits used were Cat Ref. \#038F from United Diagnostic Industries, Dammam, Saudi Arabia.

\section{Statistical methods}

The descriptive statistics and tables were created using Microsoft Excel MSO 2016 (16.0.4.266.1001) (Microsoft ${ }^{\circledR}$ Corp., Redmond, WA). Data are expressed as mean + standard deviation (SD). The comparison between G6PD deficient and non-deficient patients was made using the Student's t-test for parametric data and the Mann-Whitney $\mathrm{U}$ test for nonparametric data. A descriptive analysis of the percentages of categorical variables was done. A p-value $<0.005$ was considered to be statistically significant in all comparisons and was calculated using Epi Info ${ }^{\mathrm{TM}}$ software, version 7.2.2.7 from the Center for Disease Control and Prevention (CDC). Linear regression analysis was used for correlations.

\section{Results}

This was a retrospective study that was conducted at the Maternity and Children Hospital of Al-Ahsa, Saudi Arabia, which is the major hospital caring for children up to 14 years of age and women. There was a total of 58,431 patients admitted to the hospital over the 10 -year period of the study who had been screened for G6PD deficiency. There were 209 samples with incomplete data, and these samples were excluded from the study. Furthermore, we excluded children older than 14 years of age. A total of 48,889 samples were fully analyzed, which included 27,634 (56.5\%) male and 21,255 (43.5\%) female subjects with a mean age of $1.93+3.98$ years. The overall prevalence of G6PD deficiency was $25 \%$, with a prevalence of $33.8 \%$ among males and $13.5 \%$ among females ( $<0.0001$ ) (Table 1 ). A total of 25,628 newborn patients were admitted to the intensive care or intermediate care units, with males accounting for $55.5 \%$ and females accounting for $44.5 \%$ with an overall prevalence of G6PD deficiency of $18.8 \%$. Males had a higher rate of G6PD deficiency (26\%) compared to females $(9.9 \%)(\mathrm{p}<0.0001)$ (Table 2$)$.

\begin{tabular}{|c|c|c|c|}
\hline \multirow{2}{*}{ Gender } & \multicolumn{2}{|l|}{ G6PD status } & \multirow{2}{*}{ Total } \\
\hline & Deficient & Normal & \\
\hline Male & $9,340(33.8 \%)$ & $18,294(66.2 \%)$ & $27,634(100 \%)$ \\
\hline Female & 2,864 (13.5\%) & 18,391 (86.5\%) & $21,255(100 \%)$ \\
\hline Total & $12,204(25 \%)$ & 36,685 (75\%) & $48,889(100 \%)$ \\
\hline
\end{tabular}

TABLE 1: Prevalence of Glucose-6-Phosphate Dehydrogenase (G6PD) Deficiency in all Pediatric Patients 


\section{Cureus}

\begin{tabular}{|c|c|c|c|}
\hline \multirow{2}{*}{ Gender } & \multicolumn{2}{|l|}{ G6PD status } & \multirow{2}{*}{ Total } \\
\hline & Deficient & Normal & \\
\hline Male & 3,687 (26\%) & 10,532 (74\%) & $14,219(100 \%)$ \\
\hline Female & $1,133(9.9 \%)$ & 10,276 (90.1\%) & 11,409 (100\%) \\
\hline Total & 4,820 (18.8\%) & 20,808 (81.2\%) & $25,628(100 \%)$ \\
\hline
\end{tabular}

TABLE 2: Prevalence of Glucose-6-Phosphate Dehydrogenase (G6PD) Deficiency in Newborn

Patients

\section{Discussion}

G6PD deficiency is the most common red blood cell enzyme deficiency worldwide, affecting over 400 million individuals across the globe [19]. The clinical expression of G6PD deficiency encompasses a spectrum of disease severity related to the ability of red cells to generate NADPH (Figure 1) [3]. Likewise, the observed prevalence of $25 \%$ among the pediatric population is similar to previously reported studies in the Eastern province [15, 20], which is conversely higher than that reported in the Central, Northern, and Western regions of Saudi Arabia [20-21]. At the same time, the female pediatric population has a higher rate of G6PD deficiency (13.5\%) than the rest of the country, which can be explained by the selective nature of the study, as well as the higher rate of consanguineous marriages in the area [15, 22]. The Eastern province has the highest prevalence of G6PD deficiency in Saudi Arabia in both males and females [15, 20]. The prevalence in high-risk newborns was almost similar to the earlier studies in males (26\%) and in females (9.9\%). There is an indication of a gradual increase in the prevalence of G6PD deficiency, with the highest recorded in the age group older than one year where the overall prevalence was (24.7\%) rather than the newborn age group (18.8\%), as shown in both Tables 1 and 2 . This observation might also be an indication that the study was conducted within or closer to this age group. In this study, male children were much more affected than female children. This further reaffirmed the natural history of G6PD deficiency of being an X-linked recessive disorder, as well as the fact that only male hemizygotes and female homozygotes are the individuals most often affected. Heterozygous females can also be affected by the inactivation of one X chromosome through the Lyon hypothesis [23]. Notwithstanding the high prevalence of G6PD deficiency in the community, we lack the newborn screening (NBS) program to determine the true prevalence prospectively. The NBS program is invaluable, not only to determine the prevalence of G6PD deficiency but also plans for future monitoring for jaundice, to prevent acute encephalopathy from hyperbilirubinemia encephalopathy, and consequent observation for future hemolytic episodes [24]. Further family health education regarding chemicals, drugs, and food items that could adversely affect the patients leading to red blood cell hemolysis, jaundice, and anemia due to G6PD deficiency should be implemented. Quantitative measurement of the enzyme is also important to determine the World Health Organization (WHO) class of the disease to predict the natural course of G6PD deficiency [25].

Glucose

FIGURE 1: The glucose-6-phosphate dehydrogenase (G6PD) enzyme is the main regulator in the pentose phosphate pathway to maintain NADPH production which helps protect the red blood cells against oxidative damage

6-PG: 6-phosphogluconate; ADP: adenosine diphosphate; ATP: adenosine triphosphate; G-6-P: glucose-6phosphate; GSH: glutathione; GSSG: glutathione disulfide; NADP: nicotinamide adenine dinucleotide phosphate; NADPH: nicotinamide adenine dinucleotide phosphate 


\section{Conclusions}

The present study confirms the high prevalence of G6PD deficiency in our community. We need to establish an NBS program, according to the earlier WHO recommendation to screen for G6PD deficiency if the prevalence is above $3 \%$. Another recommendation is to screen the G6PD status during routine vaccination for those who missed NBS to enable health practitioners to protect children from preventable hemolytic episodes.

\section{Additional Information \\ Disclosures}

Human subjects: Consent was obtained by all participants in this study. Research Committee, Hereditary Blood Diseases Center issued approval HBDC-RC-005. The research committee exempted this retrospective study from the need for approval because there was no direct reference to the patient identities. Animal subjects: All authors have confirmed that this study did not involve animal subjects or tissue. Conflicts of interest: In compliance with the ICMJE uniform disclosure form, all authors declare the following: Payment/services info: All authors have declared that no financial support was received from any organization for the submitted work. Financial relationships: All authors have declared that they have no financial relationships at present or within the previous three years with any organizations that might have an interest in the submitted work. Other relationships: All authors have declared that there are no other relationships or activities that could appear to have influenced the submitted work.

\section{References}

1. Luzzatto L, Nannelli C, Notaro R: Glucose-6-phosphate dehydrogenase deficiency. Hematol Oncol Clin North Am. 2016, 30:373-393. 10.1016/j.hoc.2015.11.006

2. Howes RE, Piel FB, Patil AP, et al.: G6PD deficiency prevalence and estimates of affected populations in malaria endemic countries: a geostatistical model-based map. PLoS Med. 2012, 9:e1001339. 10.1371/journal.pmed.1001339

3. Beutler E: Study of glucose-6-phosphate dehydrogenase: history and molecular biology . Am J Hematol. 1993, 42:53-58. 10.1002/ajh.2830420111

4. Alving AS, Carson PE, Flanagan CL, Ickes CE: Enzymatic deficiency in primaquine-sensitive erythrocytes. Science. 1956, 124:484-485. 10.1126/science.124.3220.484-a

5. Lyon MF: Gene action in the X chromosome in the mouse (Mus musculus L.) . Nature. 1961, 190:372-373. 10.1038/190372a0

6. Mason PJ: New insights into G6PD deficiency . Br J Haematol. 1996, 94:585-591. 10.1111/j.13652141.1996.tb00001.x?sid=nlm\%3Apubmed

7. Harcke SJ, Rizzolo D, Harcke HT: G6PD deficiency: an update. JAAPA. 2019, 32:21-26. 10.1097/01.JAA.0000586304.65429.a7

8. Gregg XT, Prchal JT: Red cell enzymopathies. Hematology: Basic Principles and Practice. Hoffman R (ed): Churchill Livingstone, Philadelphia; 2000. 487:657-660.

9. Luzzatto L, Arese P: Favism and glucose-6-phosphate dehydrogenase deficiency . N Engl J Med. 2018, 378:60-71. 10.1056/nejmra1708111

10. Louicharoen C, Patin E, Paul R, et al.: Positively selected G6PD-Mahidol mutation reduces Plasmodium vivax density in Southeast Asians. Science. 2009, 326:1546-1549. 10.1126/science.1178849

11. Nakatsuji T, Miwa S: Incidence and characteristics of glucose-6-phosphate dehydrogenase variants in Japan . Hum Genet. 1979, 51:297-305. 10.1007/BF00283398

12. Goo YK, Ji SY, Shin HI, Moon JH, Cho SH, Lee WJ, Kim JY: First evaluation of glucose-6-phosphate dehydrogenase (G6PD) deficiency in vivax malaria endemic regions in the Republic of Korea. PLoS One. 2014, 9:e97390. 10.1371/journal.pone.0097390

13. Oppenheim A, Jury CL, Rund D, Vulliamy TJ, Luzzatto L: G6PD Mediterranean accounts for the high prevalence of G6PD deficiency in Kurdish Jews. Hum Genet. 1993, 91:293-294. 10.1007/BF00218277

14. Alharbi KK, Khan IA: Prevalence of glucose-6-phosphate dehydrogenase deficiency and the role of the Avariant in a Saudi population. J Int Med Res. 2014, 42:1161-1167. 10.1177/0300060514531923

15. Nasserullah Z, Al Jame A, Abu Srair H, Al Qatari G, Al Naim S, Al Aqib A, Mokhtar M: Neonatal screening for sickle cell disease, glucose-6-phosphate dehydrogenase deficiency and a-thalassemia in Qatif and Al Hasa. Ann Saudi Med. 1998, 18:289-292. 10.5144/0256-4947.1998.289

16. Nkhoma ET, Poole C, Vannappagari V, Hall SA, Beutler E: The global prevalence of glucose-6-phosphate dehydrogenase deficiency: a systematic review and meta-analysis. Blood Cells Mol Dis. 2009, 42:267-278. 10.1016/j.bcmd.2008.12.005

17. Dow PA, Petteway MB, Alperin JB: Simplified method for G6PD screening using blood collected on filter paper. Am J Clin Pathol. 1974, 61:333-336. 10.1093/ajcp/61.3.333

18. De Niz M, Eziefula AC, Othieno L, et al.: Tools for mass screening of G6PD deficiency: validation of the WST8/1-methoxy-PMS enzymatic assay in Uganda. Malar J. 2013, 12:210. 10.1186/1475-2875-12-210

19. Howes RE, Piel FB, Patil AP, et al.: G6PD deficiency prevalence and estimates of affected populations in malaria endemic countries: a geostatistical model-based map. PLoS Med. 2012, 9:e1001339. 10.1371/journal.pmed.1001339

20. Warsy AS, El-Hazmi MA: G6PD deficiency, distribution and variants in Saudi Arabia: an overview . Ann Saudi Med. 2001, 21:174-177. 10.5144/0256-4947.2001.174

21. Muzaffer MA: Neonatal screening of glucose-6-phosphate dehydrogenase deficiency in Yanbu, Saudi Arabia. J Med Screen. 2005, 12:170-171. 10.1258/096914105775220660 


\section{Cureus}

22. al-Abdulkareem AA, Ballal SG: Consanguineous marriage in an urban area of Saudi Arabia: rates and adverse health effects on the offspring. J Community Health. 1998, 23:75-83. 10.1023/a:1018727005707

23. Davidson RG: The Lyon hypothesis. J Pediatr. 1964, 65:765-775. 10.1016/s0022-3476(64)80163-3

24. Al-Omran A, Al-Abdi S, Al-Salam Z: Readmission for neonatal hyperbilirubinemia in an area with a high prevalence of glucose-6-phosphate dehydrogenase deficiency: a hospital-based retrospective study. J Neonatal Perinatal Med. 2017, 10:181-189. 10.3233/NPM-171696

25. WHO Working Group: Glucose-6-phosphate dehydrogenase deficiency / WHO working group . Bull World Health Organ. 1989, 67:601-611. 